Agro-Science Journal of Tropical Agriculture, Food, Environment and Extension Volume 20 Number 1 (January 2021) pp. $51-56$

ISSN 1119-7455

\title{
THE USE OF NITRITE AND ASCORBATE IN IMPROVING QUALITY OF STORED INTERMEDIATE MOISTURE (IM) SMOKED MEAT
}

\author{
"Ndife J., Ubbor S.C., Ezeocha V.C. and Olaoye O.A. \\ Department of Food Science \& Technology, \\ Michael Okpara University of Agriculture, Umudike, Nigeria \\ Corresponding author's email: jothel2000@gmail.com
}

\begin{abstract}
Smoking is one of the techniques employed to prevent spoilage of meat. Traditional smoked meat usually results in the production of over dried meat, with unattractive dark colour. This study aimed at improving quality of smoked stored meat. Beef samples were smoked before (CBS) and after (CAS) curing with nitrite and ascorbate in glycerol infusions to obtain intermediate moisture beef. The products were evaluated before and during six weeks of storage under ambient conditions for yield, pigment-conversion, residual nitrite, microbes, and sensory quality. The results of the analysis showed product yield for CBS (33.10-34.77\%) to be lower than CAS (47.43-53.48\%). Samples CAS contained more moisture (31.21-38.90\%) than CBS (24.20-28.41\%). CBS4 and CAS4 contained the highest residual nitrite values of 142 and 113 ppm, respectively. CBS4 and CAS3 had the highest myoglobin conversion of $31.31 \%$ and $74.68 \%$, respectively. Microbial count of all the beef samples increased with storage time. CBS1 and CAS1 had the highest microbial loads of 3.89 and $4.74 \log$ cful $\mathrm{g}^{-1}$. CAS samples had higher fungal growth than CBS during storage. Beef cured before smoking (CBS) had a better appearance rating (5.44-8.28) than CAS (4.78-7.39). CBS2 had the highest scores in appearance (8.28), taste (7.11) and aroma (8.06). Beef cured before smoking (CBS) had superior sensory scores than beefs cured after smoking (CAS) after six weeks of ambient storage. The quality of intermediate moisture meats was found to improve through curing, using nitrite and ascorbate.
\end{abstract}

Key words: beef, sensory, infusion, myoglobin, microbes

\section{INTRODUCTION}

Meat can be defined as the flesh of animals used for food (Ikeme, 1990; Arihara, 2006). With the rate at which the world population is increasing, it is necessary and clearly important to consider the means of satisfying the concomitant demand for nourishment. Meat with all its richness in protein and other valuable nutrients serve as a means of achieving this goal. However, meat deterioration begins soon after slaughter (Amuneke et al., 2020). In the drive to obtain meat of high quality and quantity, efforts have been directed towards meat preservation, and the most likely methods are smoking and curing (Arihara, 2006; Bryan and Loscalzo, 2011).

These methods though cheap and handy in hot climes are fraught with inconsistent qualities as the final product depends on the methods of processing and skill of the processor. More so the methods of processing vary from one locality to another depending on the processing culture in place (Ndife et. al., 2019; Amuneke et. al., 2020). In traditionally smoked meat, little or no salting is used on the meat, as preservation solely depends on moisture removal by subjecting the meat to very high temperature, which result in the production of over dried meat, with unattractive dark colour (Ikeme, 1990; Kanatt et al., 2002; Arihara, 2006).
Meat curing is defined as the application of salt or colour fixing ingredients like nitrates or nitrites and or seasoning to meat in order to impact unique properties to the end product (Rao, 1997; Sebranek and Bacus, 2007). Sodium or potassium nitrite and nitrateis used to develop cured meat colour. They impact bright reddish colour desirable in cured products. Several reductants such as ascorbic acid and ascorbates are also incorporated into meat curing mixture in order to accelerate the development of colour, flavour, texture, and palatability and enhance preservative actions (Rao,1997; Kanatt et al., 2002). However, there are limitations to the use of sodium nitrite and nitrate (Onuoha and Ndife, 2015). In food additives regulation, residual nitrite should not exceed 200 ppm in the product after curing and processing (Ali et al., 2006; Bryan and Loscalzo, 2011).

Intermediate moisture food (IMF) has been defined as partially dehydrated products that have a suitable concentration of dissolved solids to bind the remaining water sufficiently to inhibit the growth of bacteria, molds, and yeasts (Rao, 1997). IMF is shelf stable without refrigeration or thermal processing and can be eaten without rehydration. They are intermediate between fresh meats and dried meats which include Kilishi (sun-dried 
roasted meat sheets), Balangu (roasted meat slabs), Banda (hot smoked meat pieces) and Jirge (sundried fermented meat strips) (Obanu et al., 1980).

The present challenge is on how to improve the colour and texture of these traditional meat products to enhance their value and consumer acceptability as well as prolong the shelf-life. Novel meat products could be developed by employing IMF principles to improve the stability and safety of traditional meat products. One likely way of doing this is through the use of meat colour stabilizers and humectants (Arihara, 2006). This study therefore aimed at using nitrite and ascorbate with humectant to enhance the quality and sensory acceptance of smoked stored beef.

\section{MATERIALS AND METHODS}

\section{Materials Procurement and Preparation}

The meat (Longissimus dorsi of beef) was purchased from Nsukka main market. The meat was washed with water, trimmed of fat and connective tissues and cut into small lumps ca. $100 \mathrm{~g}$ each. It was sorted into 8 sets of $500 \mathrm{~g}$ of beef each for curing.

\section{Infusion Solution}

Infusion solutions with variable concentrations of sodium nitrite and ascorbate as prepared by Obanu (1976) was used (Table 1).

\section{Production of Intermediate Moisture Meat}

In the production of the intermediate moisture meat (IMM), desorption process of soak-cook method of Obanu et al. (1980) was used. An initial four sets of the beefs were cured in the pickle infusion solutions containing different concentrations of sodium nitrite and as corbate. A ratio of $500 \mathrm{~g}$ of meat to $500 \mathrm{ml}$ of the infusion solution was used. The beefs were first soaked for $15 \mathrm{~min}$. and cooked for $15 \mathrm{~min}$. After which the beefs were hot smoked for $3 \mathrm{~h}$ in a local smoking kiln (CB). Similarly, the remaining four sets of the beefs were first hotsmoked for the same period and later cured using the same procedure (CA). The samples were labeled as CBS1, CBS2, CBS3, and CBS4 for treatments cured before smoking and CAS1, CAS2, CAS3 and CAS4 for treatments cured after smoking.

\section{Storage and Sampling}

The samples of the IMM were packed in black polythene bags and stored at average room temperature of $31.95^{\circ} \mathrm{C}$, from where random samples were taken for analysis. Subsequent sampling was done at 2-week intervals. The daily temperatures and relative humidity $(\mathrm{RH})$ of the environment were monitored from a nearby meteorological station on a bi-weekly basis during the 6 weeks of storage.

\section{Physical Properties Analysis}

The product yield was determined as the difference in the weight of the fresh meat and the weight taken after curing and smoking. The moisture content of the meat samples was determined by hot air oven method (Onwuka, 2018).
Table 1: Composition of infusion solution

\begin{tabular}{lcccc}
\hline Reagents & S1 & S2 & S3 & S4 \\
\hline Potassium nitrite $(\mathrm{g})$ & - & 1.25 & 2.50 & 5.00 \\
Sodium ascorbate $(\mathrm{g})$ & - & 5.00 & 2.50 & - \\
Potassium sorbate $(\mathrm{g})$ & 2.50 & 2.50 & 2.50 & 2.50 \\
Salt $(\mathrm{g})$ & 47.50 & 47.50 & 47.50 & 47.50 \\
Glycerol $(\mathrm{ml})$ & 141.75 & 141.75 & 141.75 & 141.75 \\
Water $(\mathrm{ml})$ & 308.25 & 308.25 & 308.25 & 308.25 \\
\hline S1 - No Nitrite and Ascorbate; S2 - Low Nitrite & and High Ascorbate;
\end{tabular}

S3 - Medium Nitrite and Ascorbate; S4 - HighNitrite and No Ascorbate

\section{Meat Pigment Analysis}

The myoglobin conversion (\%) was determined using method described by Garcia-Esteban et al. (2003), in which the optical density (OD) of the sample filtrate was determined using Bauch and Lomb Spectronic 21 at wavelength of $640 \mathrm{~nm}$. The total meat pigment (ppm) was determined by the modified acetone extraction method (GarciaEsteban et al., 2003) and calculated at an absorbance of $640 \mathrm{~nm}$. The Nitroso-pigment (ppm) was also determined using the same protocol but at an absorbance of $540 \mathrm{~nm}$. The pigment-conversion (\%) was expressed as a percentage of the nitrosopigment to the total pigment (Rao, 1997).

\section{Determination of Residual Nitrite}

The nitrite content of the samples was determined by a modified AOAC (2005) method, using borax solution, zinc-acetate and potassium-ferrocyanide with napthylamine for colour development in the dark. The colour intensity was then measured spectrophotometrically at $540 \mathrm{~nm}$. Standard curve from pure sodium nitrite was used to determine the residual nitrite in the samples.

\section{Determination of Total Viable Microbial Count} The pour plate method (APHA, 1992) was used with some modifications. The final diluted solution $(1 \mathrm{ml})$ was aseptically transferred into sterile agar medium, and incubated at $37^{\circ} \mathrm{C}$ for $48-72 \mathrm{~h}$. The colonies were counted and expressed in logarithmic of colony forming unit per gram of sample ( $\left.\log \mathrm{cfu} \mathrm{g}^{-1}\right)$.

\section{Determination of Fungal Count}

The pour plate procedure was also adopted (APHA, 1992). In this case, sterile rehydrated balto-malto extract agar was used. The plates were incubated at $37^{\circ} \mathrm{C}$ for $72 \mathrm{~h}$ and the colonies were expressed as logarithm of colony forming unit per gram of sample $\left(\log \mathrm{cfu} \mathrm{g}^{-1}\right)$.

\section{Sensory Evaluation}

Aroma, appearance, texture and taste sensory attributes of beef samples were evaluated by a 24 man semi-trained panelist comprising students from Michael Okpara University of Agriculture, Umudike. The meat samples were rated on a 9-point Hedonic scale ranging from 1 (dislike extremely) to 9 (like extremely) (Iwe, 2010). 
Experimental Design and Statistical Analysis Completely randomized design was used. Data are presented as mean \pm standard deviations. The results obtained were subjected to Analysis of Variance (ANOVA) using Statistical package for social sciences (SPSS version 20). Means were separated using Duncan's multiple Range Test (DMRT). Significant difference was determined at $p<0.05$.

\section{RESULTS AND DISCUSSION Ambient Storage Condition of Intermediate Moisture Meat}

Table 2 shows the temperatures and relative humidity (RH) during the period of ambient storage. The temperature of the environment was high throughout the period of storage $\left(31.72-32.71^{\circ} \mathrm{C}\right)$. The maximum mean daily temperature recorded was during the second week of storage $\left(31.72^{\circ} \mathrm{C}\right)$. The lowest value in $\mathrm{RH}(45.00 \%)$ was recorded during the first week of storage. The ambient RH gradually increased by the fourth week $(48.10 \%)$, recording its highest value in the sixth week $(52.87 \%)$ of storage period.

\section{Product Yield of Intermediate Moisture Meat}

The percentage product yield of the intermediate moisture meat (IMM) is shown in Table 3. The product yields from treatments cured after smoking (CAS) were generally higher (47.43-53.48\%) than CBS samples cured before smoking (33.10-34.77\%). Treatment CBS4 had the lowest yield of $33.10 \%$, while CAS1 had the highest yield of $53.48 \%$. This could be due to rehydration effect resulting from curing after smoking. The reduction of beef yield relative to raw meat could be due to the drying effect of smoking, which caused the beef to shrink because of connective tissue contraction. Also, some of the meat-liquid was squeezed out, thus further reducing the weight of the beef. These exudates may contain mineral salts, extractives and small amounts of water soluble vitamins (Ikeme, 1990; Rao, 1997).

\section{Moisture Content of Intermediate Moisture Meat during Storage}

As shown in Figure 1, the samples CAS contained more residual moisture (35.31-38.91\%) than CBS (27.10-28.41\%) at the inception of storage. All the treatments continued to lose moisture as storage progressed. The initial loss in moisture was greater in CAS samples. The loss in moisture was gradual for all the samples. This could be as a result of the high ambient temperatures (Obanu et al., 1980), with mean value of $31.95^{\circ} \mathrm{C}$ during storage. The high initial loss of moisture could also be attributed to the prevalent low RH $(45.14 \%)$ of the storage environment. In the fourth to sixth weeks of storage, moisture losses became gradual; probably due to the increase in $\mathrm{RH}$ from 48.10 to $52.87 \%$. Ambient storage led to moisture loss in all the samples. The samples cured after smoking (CAS) experienced some rehydration, with increase in more residual moisture content. Thus, CAS (31.21-34.80\%) had moisture than CBS (22.80-24.61\%) during storage. The ionic nature of the curing ingredients could cause rehydration of meat samples by binding with atmospheric moisture (Arihara, 2006).

Table 2: Mean environmental temperature and relative humidity during ambient storage

\begin{tabular}{ccc}
\hline $\begin{array}{c}\text { Sampling time } \\
\text { (weeks) }\end{array}$ & $\begin{array}{c}\text { Temperature } \\
(\mathrm{C})\end{array}$ & $\begin{array}{c}\% \\
\text { Relative Humidity }\end{array}$ \\
\hline 0 & $31.72 \pm 0.66$ & $45.00 \pm 5.07$ \\
2 & $32.71 \pm 0.74$ & $45.14 \pm 3.38$ \\
4 & $31.99 \pm 0.68$ & $48.10 \pm 4.74$ \\
6 & $31.38 \pm 0.50$ & $52.87 \pm 2.92$ \\
\hline
\end{tabular}

Data represent mean values \pm standard deviation

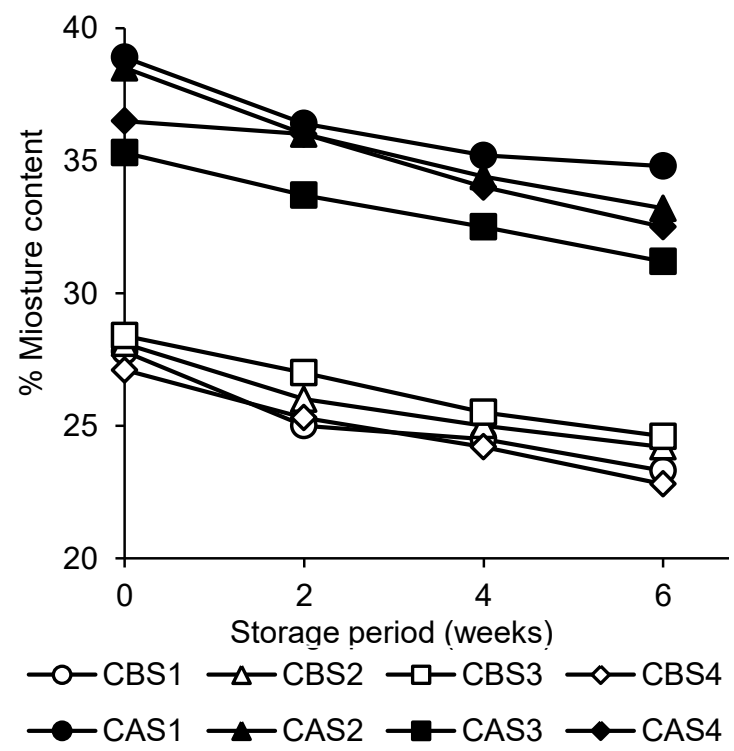

Figure 1: Moisture content of intermediate moisture meat during storage

Table 3: Product yield of intermediate moisture meat

\begin{tabular}{lllll}
\hline Sample & Raw meat $(\mathrm{g})$ & Processed meat $(\mathrm{g})$ & Weight loss $(\mathrm{g})$ & Product yield $(\%)$ \\
\hline CBS1 & $97.13 \pm 0.34$ & $32.45 \pm 0.40$ & $64.48^{\mathrm{a}} \pm 0.55$ & $33.41^{\mathrm{c}} \pm 0.80$ \\
CAS1 & $99.52 \pm 0.40$ & $53.22 \pm 0.65$ & $46.30^{\mathrm{c}} \pm 0 . .85$ & $53.48^{\mathrm{a}} \pm 0.75$ \\
CBS2 & $95.32 \pm 0.30$ & $32.05 \pm 0.30$ & $63.27^{\mathrm{a}} \pm 0.50$ & $33.63^{\mathrm{c}} \pm 0.66$ \\
CAS2 & $103.54 \pm 0.50$ & $53.80 \pm 0.81$ & $49.74^{\mathrm{b}} \pm 0.73$ & $51.96^{\mathrm{a}} \pm 0.70$ \\
CBS3 & $96.51 \pm 0.35$ & $33.56 \pm 0.62$ & $63.15^{\mathrm{a}} \pm 0.91$ & $34.77^{\mathrm{c}} \pm 0.81$ \\
CAS3 & $101.54 \pm 0.55$ & $48.16 \pm 0.73$ & $53.36^{\mathrm{b}} \pm 0.86$ & $47.43^{\mathrm{b}} \pm 0.58$ \\
CBS4 & $95.65 \pm 0.35$ & $31.64 \pm 0.48$ & $64.01^{\mathrm{a}} \pm 0.63$ & $33.10 \mathrm{c} \pm 0.63$ \\
CAS4 & $102.11 \pm 0.55$ & $51.25 \pm 0.91$ & $50.86^{\mathrm{b}} \pm 0.76$ & $50.20^{\mathrm{a}} \pm 0.77$ \\
\hline
\end{tabular}

Values are mean scores \pm standard error; Mean values in same column with different superscript are significantly $(p<0.05)$ different; CBS - Samples cured before smoking; CAS - Samples cured after smoking 


\section{Residual Nitrite of Intermediate Moisture Meat during Storage}

There were no detectable nitrites in samples CBS1 and CAS1 since they were not treated with nitrite and ascorbate. The detectable residual nitrite varied with the amount of nitrite and ascorbate used for curing (Figure 2). Samples CBS4 and CAS4 contained the highest nitrite values of $142 \mathrm{ppm}$ and $113 \mathrm{ppm}$ respectively, as they both contain no ascorbate. There were little and no residual nitrite in CBS2 (14.50 ppm) and CAS2 after 6 weeks of storage, both contained high concentrations of ascorbate (Olesen et al., 2004). More so, as storage period increased there was a steady decrease in residual nitrite detectable (Eakes and Blumer, 1975; Sebranek and Bacus 2007). Samples CAS generally, had their residual nitrite depleted faster than CBS. At the sixth week of storage, there were no detectable residual nitrites for samplesCAS2 and CAS3 which contain ascorbate.

Brown et al. (1974) reported that the addition of ascorbic acid resulted in nitrite depletion in cured meat products; this may be due to the reduction of nitrite to nitric oxide, which then reacted with meat pigments. The presence of sodium chloride could also contribute to the lowering of residual nitrite since an increase in ionic strength as a result of moisture loss could cause a decrease in $\mathrm{pH}$ which increases the solubility of nitrite (Jawad, 2012). The decrease in residual nitrite could also be the result of smoking, which resulted in the thermal degradation of nitrite (Ali et al., 2006).

\section{Myoglobin Conversion in Intermediate Moisture Meat during Storage}

The conversion of the meat pigments into its nitroso form varied directly with the nitrite and ascorbate contents of the cures (Figure 3). Samples CBS3 (108.41-81.49\%) and CAS3 (112.83-38.15\%) with medium concentrations of nitrite and ascorbate were found to give the highest myoglobin depletion. There was less myoglobin depletion in CAS samples because most of the meat protein had been denatured due to prior smoking, which slowed down the reaction of the meat pigment with nitrite. CBS1 and CAS1 (without nitrite and ascorbate) had the least pigment conversion of $12.25 \%$ and $4.63 \%$, respectively after storage. This showed that nitrite helped in colour fixation and minimized colour degradation during curing. The pigment conversion continued to decrease with ambient storage. The rapid degradation of myoglobin in treatments cured after smoking (CAS) was probably as a result of the leaching of smoke components into the cure infusion.

The colour of cured meat developed rapidly during the hot curing of the beef. The nitrosopigment (cured colour) is known to increase, with concentrations of nitrite and ascorbic acid. Ascorbic acid reduces nitrite to nitric oxide and this

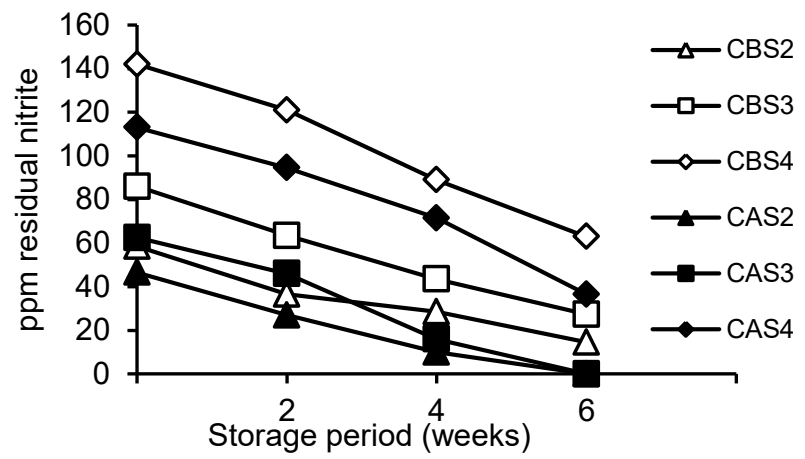

Figure 2: Residual nitrite of intermediate moisture meat during storage

combines with meat pigment to form cured meat colour, (nitrosomyoglobin) which on heating stabilizes to nitrosylhaemo chrome (Ikeme, 1990; Moller, 2002). It is also likely that the presence of sodium chloride and glycerol in the various treatments influenced the extraction of the pigments, as sodium chloride is known to increase the solubility of muscle proteins (Ikeme, 1990; Moller, 2002).

Total Viable Microbes of Intermediate Moisture Meat during Storage

As shown in Figure 4, CAS samples on the average contained higher values (4.01 $\log \mathrm{cfu} \mathrm{g}^{-1}$ ) of microbial counts, when compared to CBS (3.18 log cfu $\left.\mathrm{g}^{-1}\right)$. The control treatment CAS1 had the highest microbial load of $4.74 \log \mathrm{cfu} \mathrm{g}^{-1}$ after 6 weeks of storage. The total microbes decreased with increase in nitrite content of the cure as shown

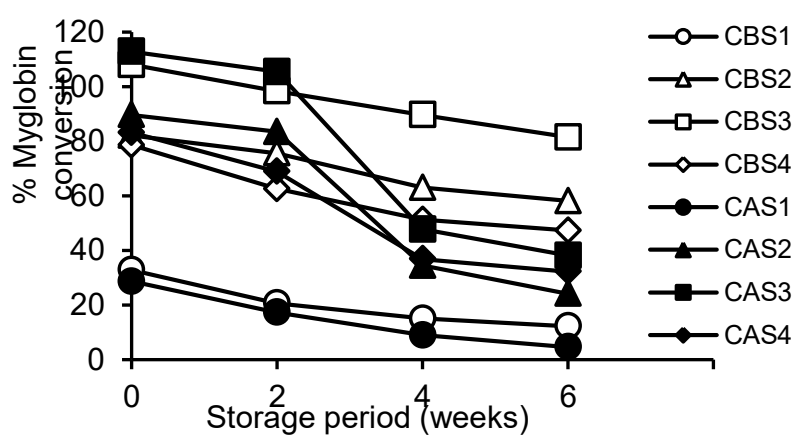

Figure 3: Myoglobin conversion of intermediate moisture meats during storage

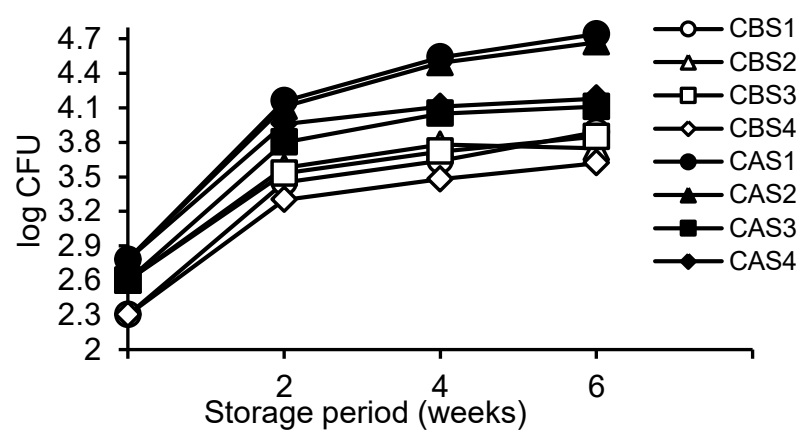

Figure 4: Total microbial counts of intermediate moisture meat during ambient storage 
by treatments CAS3 (4.11 log $\mathrm{cfu} \mathrm{g}{ }^{-1}$ ) and CBS4 $\left(3.62 \operatorname{log~cfu~~^{-1}}\right.$ ). The decrease in microbial count, observed as the nitrite content of cure increased was similar to the observation made by Moller et al. (2002). The long shelf-life of CBS samples was possibly due to the low microbial counts and the combined effects of dehydration and smoke components (Ezeama, 2007). Since these processes are known to have bactariocidal or static effect on the microorganisms (Bottexa, 2008; Goswami et al., 2013). The high microbial counts of CAS could also be due to the leaching of the antibacterial agents, like formaldehyde, phenolic and cryseolate resins, deposited on the meat surfaces during smoking and as a result of the increase in moisture content (Hasan et al., 2006; Ezeama, 2007).

\section{Fungal Counts of Intermediate Moisture Meat during Storage}

Similarly, samples CAS had higher number of fungi than CBS (Figure 5). This could be due to the high moisture content of these samples, because fungi are known to tolerate high osmotic environment (Bottexa, 2008; Goswami et al., 2013). There was a rapid increase in fungal counts during the initial periods of storage ( 2 weeks). The higher growth of fungi on CAS2 (low nitrite) and CAS1 (no nitrite) was due to their high moisture contents, both were cured after smoking, thereby resulting in their rehydration. Hot meat curing was reported by Hasan et al. (2006) to proliferate the growth of microbes, particularly fungi during prolonged ambient storage. Moreover, during the fifth to sixth weeks of ambient storage, high ambient RH up to $52.87 \%$ was recorded. This could account for moisture reabsorption by the meat samples from the atmosphere. Also the low concentrations of nitrite could also be a reason for its low-inhibiting action on the microbes (Bottexa, 2008; Goswami et al., 2013). The species of mould suspected through observed black-yellowish green colour on the meat samples are; Cladosporium, Penicillium and Aspergillus species (Ezeama, 2007).

Sensory Evaluation of Intermediate Moisture Meat The sensory scores of the intermediate moisture meats after six weeks of ambient storage is presented in Table 4 . The sensory attributes of the meat samples were significantly $(p<0.05)$ different. Beef cured before smoking (CBS) generally had superior appearance rating (5.44-8.28) than CAS (4.78-7.39). CBS2 was liked very much (8.28) while the CBS4 sample was liked slightly (6.39). The appearance of the meat samples was affected by

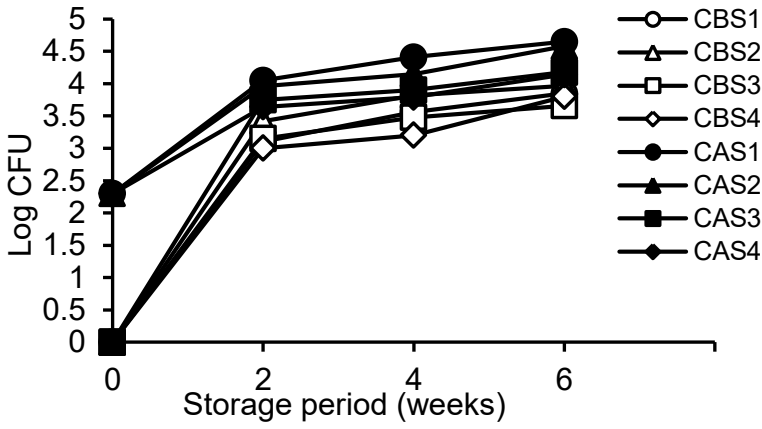

Figure 5: Fungal counts of intermediate moisture meat during ambient storage

meat curing and smoking. The attractive colours of meats treated with nitrite and ascorbate as shown by the high scores from the panelists, implied that nitrite was a colour fixator and this was enhanced by ascorbate (Olesen et al., 2004; Lundberg et al., 2009; Jawad, 2012). The gradual loss of colour in most samples on storage could be due to fading caused by the light (Jawad, 2012) and increased browning reactions, which is known to be at maximum at an intermediate moisture range (Obanu et al., 1980; Gallego-Restrepo et al., 2013). Moreover, the pigments may have been oxidized from nitric-oxide myohaemocrome to brownish red metmyoglobin (Ikeme, 1990; Moller et al., 2002).

CBS samples had superior taste scores (5.22-7.39) than CAS (3.50-5.78). The CAS samples were at best neither liked nor disliked by the panelists. This was probably as a result of smoke deposition, which has been reported to improve the palatability of meat, mostly through its phenolic and aldehyde components (Jawad, 2012). The low taste scores of CAS could also be as a result of glycerol interfering in their flavour. The high taste scores of samples cured with ascorbate, showed that ascorbic acid, helped to retain the flavour of cured meats (Brown et al., 1974; Moller et al., 2002). Samples cured with nitrite also had higher flavour scores when compared to the controls CBS1 (5.22) and CAS1 (3.50). This showed that nitrite contributed to the development of cured flavour in these intermediate moisture meats (Eakes and Blumer, 1975; Lundberg et al., 2009). The increase in taste scores of CBS samples with aging was supported by work done by Brown et al. (1974) and Moller et al. (2002). The low taste scores of CAS samples could also be due to higher microbial contents which affected their organoleptic qualities (Lundberg et al., 2009; Gallego-Restrepo et al., 2013).

Table 4: Sensory evaluation of intermediate moisture meat

\begin{tabular}{lcccc}
\hline Samples & Appearance & Taste & Texture & Aroma \\
\hline CBS1 & $5.44^{\mathrm{c}} \pm 0.57$ & $5.22^{\mathrm{c}} \pm 0.80$ & $5.16^{\mathrm{d}} \pm 0.35$ & $5.00^{\mathrm{d}} \pm 0.37$ \\
CAS1 & $4.78^{\mathrm{d}} \pm 1.21$ & $3.50^{\mathrm{d}} \pm 0.79$ & $4.11^{\mathrm{e}} \pm 1.26$ & $4.28^{\mathrm{e}} \pm 0.94$ \\
CBS2 & $8.28^{\mathrm{a}} \pm 0.05$ & $7.22^{\mathrm{a}} \pm 0.46$ & $7.11^{\mathrm{a}} \pm 0.30$ & $8.06^{\mathrm{a}} \pm 0.40$ \\
CAS2 & $7.39^{\mathrm{b}} \pm 0.44$ & $5.78^{\mathrm{b}} \pm 0.46$ & $4.78^{\mathrm{d}} \pm 0.78$ & $6.00^{\mathrm{c}} \pm 1.30$ \\
CBS3 & $8.22^{\mathrm{a}} \pm 0.15$ & $7.39^{\mathrm{a}} \pm 0.64$ & $6.51^{\mathrm{b}} \pm 0.20$ & $7.94^{\mathrm{a}} \pm 0.55$ \\
CAS3 & $6.83^{\mathrm{b}} \pm 1.11$ & $5.94^{\mathrm{c}} \pm 0.95$ & $5.22^{\text {cd }} \pm 0.72$ & $6.44^{\mathrm{bc}} \pm 0.92$ \\
CBS4 & $6.39^{\mathrm{bc}} \pm 0.56$ & $5.83^{\mathrm{c}} \pm 0.25$ & $6.67^{\mathrm{b}} \pm 0.73$ \\
CAS4 & $5.56^{\mathrm{c}} \pm 1.01$ & $4.89^{\mathrm{c}} \pm 0.40$ & $5.61^{\mathrm{c}} \pm 0.63$ & $5.39^{\mathrm{d}} \pm 0.87$ \\
\hline
\end{tabular}

Values are mean scores \pm standard error; Mean values in same column with different superscript are significantly $(p<0.05)$ different;

CBS - Samples cured before smoking; CAS - Samples cured after smoking 
CBS samples had higher texture scores (5.16-7.11), because of their hardness derived from the dryingout effect of hot smoking after curing. CBS2 was liked moderately (7.11) compared to CBS3 which was fairly liked (6.51) and CBS4 that was neither liked nor disliked (5.83) by the panelists. This could be due to reasons given by Brown et al. (1974), that nitrite cured without ascorbic acid has been shown to increase the hardness of meat, as ascorbic acid tends to mellow the texture of cured meats. The high aroma scores of CBS2 (8.06) and CAS3 (6.44) could be due to the positive influence of nitrite and ascorbic acid on flavour as reported by Eakes and Blumer (1975) and Moller et al. (2002). The low aroma scores of CBS1 (5.00) and CAS1 (4.28) by the panelists, could be as a result of deteriorative changes in the treatments, caused by their initial high moisture contents and hence high microbial loads (Pegg and Shahidi, 2000; Goswami et al., 2013).

\section{CONCLUSION}

This study demonstrated that the quality of intermediate moisture smoked meats improved by curing with nitrite and ascorbate. There was less myoglobin depletion in samples cured after smoking (CAS). Samples without nitrite and ascorbate (CBS1 and CAS1) had the least pigment conversion after storage. The total microbes in the samples decreased with increase in nitrite content of the cure. Ascorbate treated meats improved organoleptic attributes more than non-ascorbate treated samples. Moreover, the level of enhancement of the sensory attributes was best for medium nitrite and ascorbate infusion, followed by low nitrite and high ascorbate treated samples. Generally, intermediate moisture meats cured before smoking (CBS) had superior organoleptic scores than intermediate moisture meats cured after smoking (CAS) after six weeks of ambient storage.

\section{REFERENCES}

Ali T., Aylin A., Libige S. and Mine U. (2006). Determination of nitrate and nitrite content of Turkish cheese. Afr. J. Biotechnol., 5, 1411-1414

Amuneke K.E., Oguntade O.R., Ikeogu F.C. and Nomeh U.A. (2020). Effect of natural preservatives on the organoleptic characteristics and storage stability of smoked Heterotis niloticus. Agro-Science, 19 (2), 31-35

AOAC (2005). Official Methods of Analysis (16 $\left.6^{\text {th }} \mathrm{ed}.\right)$, Association of Official Analytical Chemists, Washington, D.C., p. 1038

APHA (1992). Compendium of Methods for the Microbiological Examination of Foods $\left(4^{\text {th }}\right.$ ed.), Am. Public Health Assoc., Washington, DC, pp. 95-112

Arihara K. (2006). Strategies for designing novel functional meat products. Meat Science, 74:219-229

Bottexa B., Dorne J., Carlandera D., et al. (2008). Risk-benefit health assessment of food-food fortification and nitrate in vegetables. Trends Food Sci. Technol., 19, 113-119

Bryan N.S. and Loscalzo J. (2011). Nitrite and nitrate in human health and disease. In A. Bendich (ed.), Nutrition and Health (pp. 165-179). Humana Press, New York

Brown C.1., Hendrick B.H. and Deuley M.H. (1974). Characteristics of cured ham as influenced by levels of sodium nitrite and sodium ascorbate. J. Food Sci., 39, 977-985
Eakes B.S. and Blumer T.N. (1975). The effect of nitrite and nitrate on the flavor of country style ham. J. Food Sci., 40, 93-98

Ezeama C.F. (2007). Food Microbiology: Fundamentals and Applications. Natural Prints Ltd Lagos, pp. 65-68

Gallego-Restrepo J., Ochoa O. and Perez-Alvarez J. (2013). Use of celery extract and starter culture (Staphylococcus carnosus) as an alternative sources of sodium nitrite in cooked ham: influence upon colour. J. Meat Sci. Technol., 1 (1), 12-20

Garcia-Esteban M., Ansorena D., Gimeno O. and Stiasar N. (2003). Optimization of instrumental colour analysis in dry-cured ham. Meat Sci., 63 (3), 287-292

Goswami M., Prabhakarn P. and Tanwar K. (2013). Comparative study of spices and condiments mix as nitrite replacer for reducing microbial load in chicken mince. J. Meat Sci. Technol., 1 (3), 91-97

Hasan Y., Ahmad K., Zulal K. and Osman S. (2006). The effects of nitrite on the survival of Clostridium sporogenes and the autoxidation properties of the kavurma. Meat Sci., 72, 206-210

Ikeme A.I (1990). Meat Science and Technology: A Comprehensive Approach, Africana-FepPubl., Ltd. Onitsha, Nigeria, pp. 67-72

Iwe M.O. (2010). Hand Book of Sensory Methods and Analysis, Rojoint Communication Services Ltd. Enugu, Nigeria, pp. 75-80

Jawad I. (2012). Estimation of nitrite, nitrate and Nnitosoamines in selected food samples. Pakistan $J$. Nutr., 11 (5), 481-483

Kanatt S.R.., Chawla S.P. and Chander R. (2002). Shelf-stable and safe intermediate-moisture meat products using hurdle technology. J. Food Protection, 65 (10), 1628-1631

Lundberg J.O., Gladwin M.T., Ahluwalia A., Benjamin N., Bryan N.S. and Butler A. (2009). Nitrate and nitrite in biology, nutrition and therapeutics. Nature Chem. Biol., 5 (12), 865-869

Moller J.K. and Skibsted L.H. (2002). Nitric oxide and myoglobins. Chemical Reviews, 102 (4), 1167-1178

Ndife J, Ahmad T.B., Dandago M.A. and Gambo A. (2019). Comparative quality assessment of commercial sun dried catfish (Clarias garienpinus) from Kano and Wudil Metropolises, Nigeria. Bayero J. Pure Appl Sci, 12 (1), 132-140

Obanu Z.A. (1976). Meat preservation at intermediate water activity. J. Food Sci. Agric., 27, 290-298

Obanu Z.A., Leward D.A. and Lawrie R.A. (1980). Lipid protein interaction as agents of quality deterioration in intermediate moisture meat. Meat Sci., 4, 79-88

Olesen P.T., Stahnke L.H. and Talon R. (2004). Effect of ascorbate, nitrate and nitrite on the amount of flavour compounds produced from leucine by Staphylococcus xylosus and Staphylococcus carnosus. Meat Sci., 68 (2), 193-200

Onuoha C. and Ndife J. (2015). Food Processing Additives, Amotes Link Services \& Publishers, Kaduna, Nigeria, pp. 57-62

Onwuka G.I. (2018). Food Analysis and Instumentation: Theory and Practice ( $2^{\text {nd }}$ ed.), Napthali Prints Shomolu Lagos, Nigeria, pp. 122-128

Pegg R. and Shahidi F. (2000). Nitrite Curing of Meat: The N-Nitrosamine Problem and Nitrite Alternatives, Food \& Nutrition Press Inc. Connecticut, USA

Rao N. (1997). Intermediate moisture foods based on meats-a review. Food Rev. Int., 13 (4), 519-51

Sebranek J. and Bacus J. (2007). Cured meat products without direct addition of nitrate or nitrite: what are the issues Meat Sci., 77, 136-145 